\title{
Conversion kinetics of rapid photo-polymerized resin composites
}

DOI:

10.1016/j.dental.2020.07.008

\section{Document Version}

Accepted author manuscript

Link to publication record in Manchester Research Explorer

\section{Citation for published version (APA):}

Algamaiah, H., Silikas, N., \& WATTS, D. C. (2020). Conversion kinetics of rapid photo-polymerized resin composites. Dental Materials, 36(10), 1266-1274. https://doi.org/10.1016/j.dental.2020.07.008

\section{Published in:}

Dental Materials

\section{Citing this paper}

Please note that where the full-text provided on Manchester Research Explorer is the Author Accepted Manuscript or Proof version this may differ from the final Published version. If citing, it is advised that you check and use the publisher's definitive version.

\section{General rights}

Copyright and moral rights for the publications made accessible in the Research Explorer are retained by the authors and/or other copyright owners and it is a condition of accessing publications that users recognise and abide by the legal requirements associated with these rights.

\section{Takedown policy}

If you believe that this document breaches copyright please refer to the University of Manchester's Takedown Procedures [http://man.ac.uk/04Y6Bo] or contact uml.scholarlycommunications@manchester.ac.uk providing relevant details, so we can investigate your claim.

\section{OPEN ACCESS}




\title{
Conversion kinetics of rapid photo-polymerized resin composites
}

Short Title: Rapid Photo-Cure Composites

\author{
Hamad Algamaiah ${ }^{1,3}$; Nikolaos Silikas ${ }^{1}$; David C Watts ${ }^{1,2}$ \\ ${ }^{1}$ Biomaterials Science, Division of Dentistry, School of Medical Sciences, University of \\ Manchester, UK \\ ${ }^{2}$ Photon Science Institute, University of Manchester, UK \\ ${ }^{3}$ Department of Restorative Dental Sciences, College of Dentistry, King Saud University, \\ Saudi Arabia
}

\section{Corresponding authors:}

\section{Dr Hamad Algamaiah}

Department of Restorative Dental Sciences,

College of Dentistry,

King Saud University,

Riyadh

Saudi Arabia

Email: dr.algamaiah@gmail.com

Prof. David C Watts

University of Manchester,

School of Medical Sciences and Photon Science Institute

Coupland 3 Building,

Oxford Road,

Manchester M13 9PL, UK

Email: david.watts@manchester.ac.uk 


\title{
Conversion kinetics of rapid photo-polymerized resin composites
}

\begin{abstract}
Objective: To measure the degrees of conversion (DC), conversion kinetics, and the effect of postirradiation time on rapid photo-polymerized bulk-fill resin composites under conditions equivalent to clinical depths of 1 and $4 \mathrm{~mm}$.
\end{abstract}

Methods: 36 specimens ( $n=3)$, based on two resin composites incorporating PowerCure rapidpolymerization technology in two consistencies (PFill; PFlow) and two comparators with matching consistencies (Eceram; EFlow), were investigated from the same manufacturer (Ivoclar AG, Liechtenstein). Specimens were prepared within $4 \mathrm{~mm}$ diameter cylindrical molds, of either $1 \mathrm{~mm}$ or $4 \mathrm{~mm}$ depths respectively, to simulate near-surface and deep locations in a bulk-fill restoration. The independent variables in this study were: materials, thickness and time. Two high irradiance polymerization protocols were utilized for PowerCure materials: 2000 and $3050 \mathrm{~mW} / \mathrm{cm}^{2}$ for 5 and $3 \mathrm{~s}$, respectively. A standard $\left(1200 \mathrm{~mW} / \mathrm{cm}^{2}\right)$ polymerization protocol was used with control materials. FTIR was utilized to measure DC in real-time for $24 \mathrm{~h}$ post-irradiation. The data were analyzed using multiple Welch's-ANOVA, Games-Howell post-hoc test, kinetic dual-exponential sum function and multiple independent sample $t$-tests $(p=0.05)$.

Results: The DC of the materials ranged between $44.7-59.0 \%$ after $5 \mathrm{~min}$, which increased after $24 \mathrm{~h}$ reaching $55.7-71.0 \%(p<0.05)$. Specimen thickness did not influence the overall DC. At 5 min, the highest DC was shown in EFlow. But PFlow, irradiated for $3 \mathrm{~s}$ and $5 \mathrm{~s}$ exhibited comparable results $(p<0.05)$. PFill composite irradiated with the $3 \mathrm{~s}$ and $5 \mathrm{~s}$ protocols did not differ from ECeram $(p<0.05)$. Specimen thickness and material viscosity affected polymerization kinetics and rate of polymerization $\left(\mathrm{RP}_{\max }\right)$. Faster polymerization occurred in $1 \mathrm{~mm}$ specimens (except PFill-5s and ECeram).. PFill and PFlow exhibited faster conversion than the controls. $\mathrm{RP}_{\max }$ varied across the specimen groups between 4.3-8.8 \%/s with corresponding DC ${ }_{\text {RPmax }}$ between 22.2-45.3 \%.

Significance: Polymerization kinetics and $\mathrm{RP}_{\max }$ were influenced by specimen thickness and material viscosity. PFill and PFlow materials produced an overall comparable conversion at $5 \mathrm{~min}$ and $24 \mathrm{~h}$ post-irradiation, despite the ultra-short irradiation times, throughout the $4 \mathrm{~mm}$ specimen thickness. Keywords: Resin composite; Photopolymerization; FTIR; Degree of Conversion; AFCT; Polymerization kinetics. 


\section{Introduction}

A representative general dentist spends more than half of their clinical time placing direct restorations, most of which are resin composites [1]. These have become the preferred type of direct restorative materials owing to the recent advancements in their properties. Furthermore, dentists are always looking for an efficient way to manage their practice including fast set materials and shortened clinical steps to reduce overall expenses.

This was endorsed by composite manufacturers via recent facilitation in resin composite application, with less clinical steps and shorter photo-polymerization time. However, this requires operators to develop increased understanding of their materials and their applications [1-3]. Even though the polymerization reaction is essentially chemical, operators still control some key aspects of the reaction. The radiant energy and exposure time determine the amount of energy delivered to excite the photoinitiators and thus the rate and quality of polymerization [4, 5]. Also, the selected filler load, shade, increment thickness, distance and angulation of light-curing tip are all operator-related factors that affect material behavior upon polymerization and future properties [6-8]. Sub-optimal delivery of energy can cause low degree of conversion and physical instability leading to further complications such as marginal deterioration, recurrent caries, and bulk fracture [914].

Photo-polymerization of resin composite begins as light propagates through the material depth. Photon energy activates the free radical generators (photoinitiators). Depending on the photoinitiator type (Norrish type I, II), these photoinitiators will generate free radicals seeking another electron to bond with. Methacrylate groups, in most dental monomers, will instantly bond to the free radical, at one end of the $(C=C)$ double bond. The other end will become a radical and the reaction will continue to propagate. This chain reaction will autoaccelerate rapidly, until the concentration of the available monomers diminishes and/or the densification process limits the monomer movements and hinders further reaction [15]. Random rapid crosslinking can ultimately reduce molecular movements, resulting in a nonhomogeneous network and potentially a less-than-optimal DC. This can lead to future 
elution of unreacted monomers, causing compromised physical stability and mechanical properties [16].

One approach to improve the physical stability of the resin composites is by controlling the polymer network architecture through the radical polymerization. The idea is that by modifying the radical chain growth to a step-like polymerization, a more homogenous polymer network with improved physical and mechanical properties will be achieved. The reversible addition-fragmentation chain transfer (RAFT) polymerization mechanism, by the addition of $\beta$-allyl sulfone (AFCT) reagent, was proposed previously to be incorporated in dental polymers [17]. Incorporating (AFCT) reagent to a dimethacrylate network has been shown to improve the network architecture during polymerization leading to enhanced network homogeneity, thermal glass transition temperature, and mechanical properties [17, 18]. This promising modification was utilized in a bulkfill resin composite materials as part of a restorative system, PowerCure, (PowerFill and PowerFlow; Ivoclar Vivadent AG, Liechtenstein). These restorative materials were designed to work with high irradiance $\left(3050 \pm 10 \% \mathrm{~mW} / \mathrm{cm}^{2}\right)$ received from a polywave light-curing unit (LCU: Bluephase PowerCure).

The efficacy of polymerization may decrease in deep layers due to light attenuation in 2-3 $\mathrm{mm}$ depth. A reduced number of photons reaching the bottom layer means fewer activated photoinitiator molecules $[19,20]$. Therefore, the bottom layer DC is important to understand polymerization-related properties. Fourier transform infrared (FTIR) spectroscopy is routinely used to measure DC [21]. The mid-IR spectrum ranges between $4000-400 \mathrm{~cm}^{-1}$ which interacts with molecular vibration modes [21, 22]. Following irradiation, polymerization may continue for more than 7 days post-irradiation [23]. However, $24 \mathrm{~h}$ post irradiation measurements are sufficient to determine polymer matrix formation $[5,20]$.

The effect of using such high irradiance light-curing units is still not fully explored. Therefore, the aim of this study was to evaluate the degree of conversion (DC), conversion kinetics, and the effect of $24 \mathrm{~h}$ post-irradiation time on rapid photo-polymerized resin composites at depths-within-specimens of 1 and $4 \mathrm{~mm}$, relative to the irradiated surface. The null hypotheses were that: there are no differences in the DC between rapid photo- 
polymerized resin composites and conventional photo-polymerized comparator composites: (a) at 1 and $4 \mathrm{~mm}$ depths; and (b) for $5 \mathrm{~min}$ and $24 \mathrm{~h}$ post-irradiation times.

\section{Materials and methods}

\section{Study design}

The independent variables in this study were: materials, thickness, and time. Two resin composite materials incorporating rapid-polymerization technology and two comparators were investigated. Data on the resin composite compositions were obtained from the manufacturer (Table 1, Figure 1). PowerCure materials are available in flowable (lower viscosity) and non-flowable (regular viscosity) consistencies. Two comparator materials were studied with matching consistencies. The purpose of this study was to investigate the PowerCure materials within their system. Therefore, two high irradiance light protocols were utilized for the PowerCure materials: $2000 \mathrm{~mW} / \mathrm{cm}^{2}$ for $5 \mathrm{~s}$ and $3050 \mathrm{~mW} / \mathrm{cm}^{2}$ for $3 \mathrm{~s}$, respectively. A standard $\left(1200 \mathrm{~mW} / \mathrm{cm}^{2}\right)$ light curing unit (LCU) was used with the control materials (Table 2 ). The radiant emittances were all verified with a calibrated MARC ${ }^{\text {TM }}$-LC instrument (BlueLight Analytics, Halifax, Ca). 


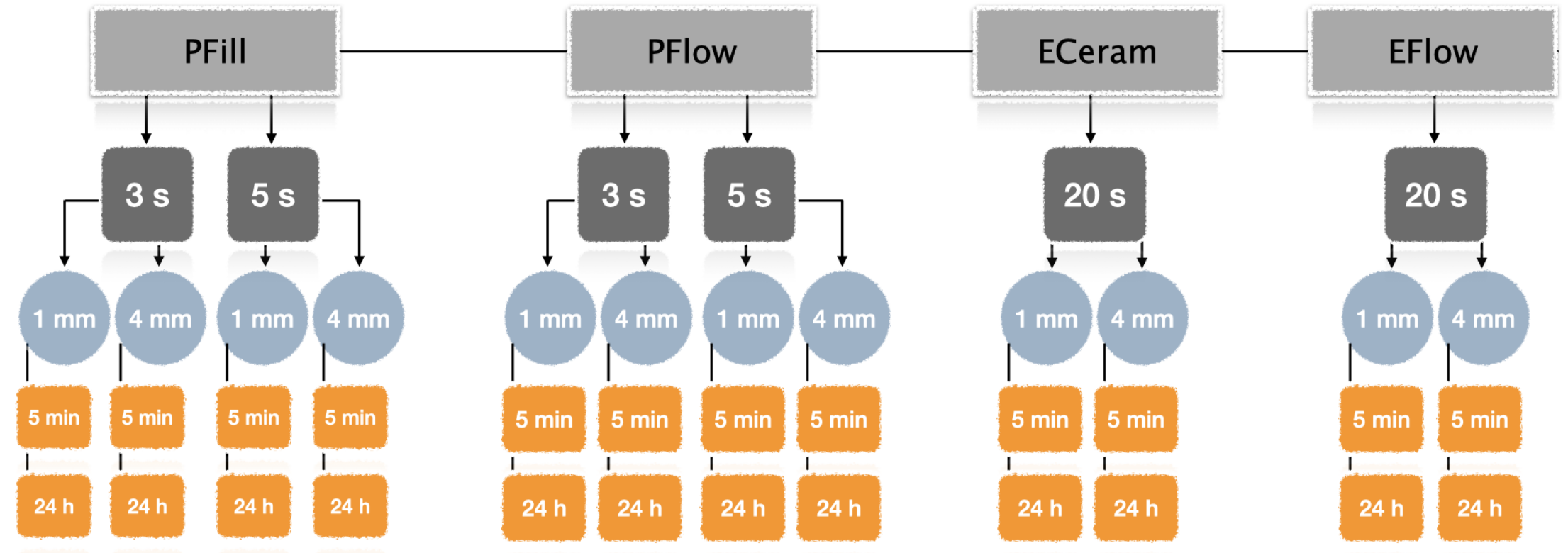

Figure 1: Representation of the study design $(n=3)$ 


\section{Specimen preparation}

Specimens were prepared within $4 \mathrm{~mm}$ cylindrical molds of either 1 or $4 \mathrm{~mm}$ depth (thickness) to simulate, respectively, near-surface and deep locations in bulk-fill restorations. All specimens were fabricated and measured at $23 \pm 1{ }^{\circ} \mathrm{C}$. Twelve specimen groups $(n=3)$ were created for each permutation of material /irradiation protocol and the two measurement depths [Tables: 1, 2, 4]. The sample size was confirmed using G*power software (V. 3.1.3; Heinrich Heine University, Germany) based on a pilot study. A sample size: $\mathrm{n}=3$ was sufficient to give a power over $80 \%$.

Table 1: Materials used in this study. All manufactured by Ivoclar-Vivadent AG, Liechtenstein

\begin{tabular}{|c|c|c|c|c|}
\hline $\begin{array}{l}\text { Material } \\
\text { code }\end{array}$ & Product name & $\begin{array}{l}\text { Lot } \\
\text { number }\end{array}$ & Resin matrix* & $\begin{array}{l}\text { Filler load } \\
\% \\
\text { (wt);(vol) }\end{array}$ \\
\hline PFill & Tetric PowerFill & W92823 & \multirow{2}{*}{$\begin{array}{l}\text { Bis-GMA, Bis-EMA, } \\
\text { UDMA, Aromatic } \\
\text { Dimethacrylate, DCP }\end{array}$} & $79 \% ; N A$ \\
\hline PFlow & Tetric PowerFlow & WM1175 & & $71 \%$; NA \\
\hline ECeram & $\begin{array}{l}\text { Tetric EvoCeram } \\
\text { Bulk Fill }\end{array}$ & U53769 & $\begin{array}{l}\text { Bis-GMA, Bis-EMA and } \\
\text { UDMA }\end{array}$ & $80 ; 61 \%$ \\
\hline EFlow & $\begin{array}{l}\text { Tetric EvoFlow } \\
\text { Bulk Fill }\end{array}$ & U42390 & $\begin{array}{l}\text { Bis-GMA, Bis-EMA, } \\
\text { TCDD }\end{array}$ & $68.2 ; 46.4 \%$ \\
\hline \multicolumn{5}{|c|}{$\begin{array}{l}\text { *Matrix monomer: Bis-GMA: bisphenol-A-diglycidyl dimethacrylate; Bis-EMA: } \\
\text { bisphenol-A-polyethylene-glycol-diether dimethacrylate; UDMA: urethane } \\
\text { dimethacrylate. }\end{array}$} \\
\hline \multicolumn{5}{|c|}{$\begin{array}{l}\text { Filler percentages and contents reported by the manufacturers. Typical content: } \\
\mathrm{Ba} / \mathrm{Al} \text { - silicate glass, Isofiller, } \mathrm{YbF}_{3} \text {, spherical mixed oxide. }\end{array}$} \\
\hline
\end{tabular}

Table 2: Light-curing units.

\begin{tabular}{|c|c|c|c|c|c|c|}
\hline $\begin{array}{l}\text { Light-curing } \\
\text { unit }\end{array}$ & $\begin{array}{l}\text { Emission } \\
\text { spectral } \\
\text { type }\end{array}$ & Protocol & Time & $\begin{array}{l}\text { Irradiance } \\
\mathrm{mW} / \mathrm{cm}^{2}\end{array}$ & $\begin{array}{l}\text { Radiant } \\
\text { exposure } \\
\mathrm{J} / \mathrm{cm}^{2}\end{array}$ & Manufacturer \\
\hline \multirow{2}{*}{$\begin{array}{l}\text { Bluephase } \\
\text { PowerCure } \\
\text { (P-Cure) }\end{array}$} & \multirow{2}{*}{$\begin{array}{l}\text { wide } \\
\text { spectrum }\end{array}$} & $3 \mathrm{~s}$ & $3 s$ & 3000 & 9 & \multirow{2}{*}{$\begin{array}{l}\text { Ivoclar } \\
\text { Vivadent AG, } \\
\text { Liechtenstein }\end{array}$} \\
\hline & & Turbo & $5 \mathrm{~s}$ & 2000 & 10 & \\
\hline $\begin{array}{l}\text { Elipar S10 } \\
\text { (S10) }\end{array}$ & $\begin{array}{l}\text { narrow } \\
\text { spectrum }\end{array}$ & Standard & $20 \mathrm{~s}$ & 1200 & 24 & $\begin{array}{l}\text { 3M ESPE, MN, } \\
\text { USA }\end{array}$ \\
\hline
\end{tabular}




\section{Degree of Conversion}

The DC of the materials was measured by a Fourier-transform infrared (FTIR) spectrometer (ALPHA II, Bruker, Massachusetts, USA), with a single reflection ATR accessory (Figure 2). Uncured composite materials, within 1 or $4 \mathrm{~mm}$ deep molds, were placed over the ATR crystal (Figure 3). The spectrum of each uncured material was recorded for the duration of two scans (10 s). The specimens were then irradiated using the designated LCU, for specified periods (Table 2). Using OPUS software (BRUKER OPTIK GmbH, Ettlingen, Germany), FTIR spectra were recorded in real-time for $24 \mathrm{~h}$ post-irradiation. That is, each specimen remained in position at $23^{\circ} \mathrm{C}$ on the ATR crystal for $24 \mathrm{~h}$, while spectra were recorded continuously. Subsequently, from the resultant datasets, DC (\%) values at selected relevant time intervals ( $5 \mathrm{~s}, 60 \mathrm{~s}, 5 \mathrm{~min}, 24 \mathrm{~h}$ ) were plotted as a function of $\log _{10}$ time (s), (Figure 3). The parameters were as follows: $4000-400 \mathrm{~cm}^{-1}$ wavelength; $4 \mathrm{~cm}^{-1}$ resolution. The instrument was calibrated daily by generating a background spectrum to be implemented in the specimen's spectrum.

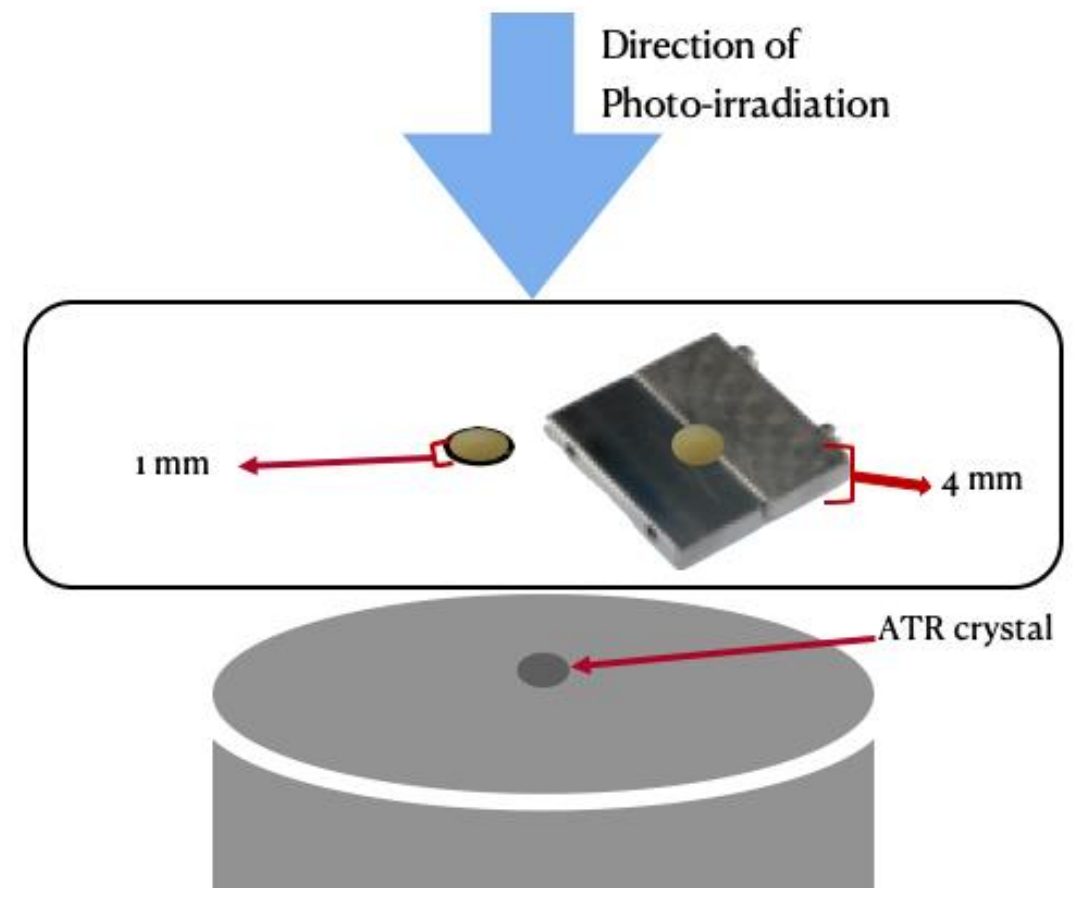

Figure 2: Schematic representation of the DC measurement using FTIR. Two different mold types were used to fabricate $1 \mathrm{~mm}$ and $4 \mathrm{~mm}$ thick specimens each of $4 \mathrm{~mm}$ diameter (to cover ATR crystal). The distance from the LCU optic tip to specimen surface was $0 \mathrm{~mm}$. The FTIR spectra were obtained from the lower specimen surfaces. 
To calculate $D C$, the variation in peak height ratio using the two-frequency technique $(C=C$ stretch at $1637 \mathrm{~cm}^{-1}$ against an internal reference frequency at $1608 \mathrm{~cm}^{-1}$ ) was utilized. The per-cent degree of conversion, from equation 1, was calculated and plotted over time.

DC $\%=\left[1-\left(\frac{\left(\frac{1637 \mathrm{~cm}^{-1}}{1608 \mathrm{~cm}^{-1}}\right) \text { peak heights after polymerization }}{\left(\frac{1637 \mathrm{~cm}^{-1}}{1608 \mathrm{~cm}^{-1}}\right) \text { peak heights before polymerization }}\right)\right]$ X 100

An average of 20 scans were used to obtain spectral data at $5 \mathrm{~min}$ and $24 \mathrm{~h}$ post-irradiation. Closer analysis of the $\mathrm{C}=\mathrm{C}$ double bond conversion over the first $300 \mathrm{~s}$ was conducted via a dual-exponential sum function, defined by the parameters $a, b, c$, and d (equation 2) $D C=a \cdot\left(1-e^{-b . t}\right)+c \cdot\left(1-e^{-d . t}\right)$

Eq. 2

Here: $a, b, c, d$ are modulation factors to optimally fit the model function to the experimental curves of DC versus time ( $t)$. These parameters represent propagation of polymerization in which " $a$ " and " $b$ " parameters correspond to the gel phase. The second pair of parameters, " $c$ " and " $d$ ", correspond to the onset of vitrification, when the material enters the glassy state. The rate of $\mathrm{C}=\mathrm{C}$ double bond conversion over time $\left(\mathrm{RP}_{\max }\right)$ was calculated and plotted. The $\mathrm{DC}_{\mathrm{RP} \max }$, correspondent to $\left(\mathrm{RP}_{\max }\right)$, was also calculated and tabulated.

\section{Statistical analysis}

The Shapiro-Wilk test confirmed normality of the data distribution. However, the equality of variance assumption failed Levene's test. Therefore, the data were analyzed using multiple Welch's ANOVA, followed by the Games-Howell post-hoc test at $5 \%$ level of significance. Additionally, multiple independent sample t-tests were utilized to evaluate the effect of specimen depth and post-irradiation time $(p=0.05)$. 


\section{Results}

\section{Degree of Conversion}

The effect of the materials and time on the DC were statistically significant $(p<0.05)$ (Figure 3; Table 3). The DC of the materials ranged between $44.7-59.0 \%$ after $5 \mathrm{~min}$, which increased after $24 \mathrm{~h}$ reaching $55.7-71.0 \%$. Subsequent analysis - comparing materials based on their viscosity (Flowables/non-flowables) - showed higher conversion of flowable materials versus non-flowables. EFlow had generally the highest DC at $5 \mathrm{~min}$ and $24 \mathrm{~h}$, regardless of the thickness. DC for PFlow specimens, irradiated for $3 \mathrm{~s}$ and $5 \mathrm{~s}$, were comparable to EFlow for all times and both depths $(p<0.05)$. similarly, PFill composite irradiated for $3 \mathrm{~s}$ and $5 \mathrm{~s}$, did not differ from ECeram comparator material $(p<0.05)$. All materials increased in DC after $24 \mathrm{~h}$ post-irradiation. More specifically, all flowable materials, along with $1 \mathrm{~mm}$ thick PFill -3s, significantly increased in DC after $24 \mathrm{~h}(\mathrm{p}<0.05)$.

Table 3: Degrees of Conversion (DC \%), of specimens at 1 and $4 \mathrm{~mm}$ depths, at $5 \mathrm{~min}$ and $24 \mathrm{~h}$ post-irradiation. Different lower-case letters compare materials and depths, within each time point. Different capital letters across rows represent statistically significant differences between times.

\begin{tabular}{|c|c|c|c|c|}
\hline \multirow{3}{*}{ Materials } & \multicolumn{4}{|c|}{ DC \% } \\
\hline & \multicolumn{2}{|l|}{$5 \mathrm{~min}$} & \multicolumn{2}{|l|}{$24 \mathrm{~h}$} \\
\hline & $1 \mathrm{~mm}$ & $4 \mathrm{~mm}$ & $1 \mathrm{~mm}$ & $4 \mathrm{~mm}$ \\
\hline Pfill-3s & $50.1(0.7)^{c d A}$ & $46.1(4.7)^{a b c A}$ & $61.1(1.5)^{C B}$ & $60.9(6.6)^{a b c A}$ \\
\hline Pfill-5s & $46.2(4.4)^{a b c A}$ & $44.7(2.1)^{\mathrm{bcA}}$ & $57.9(8.2)^{\mathrm{abcA}}$ & $55.7(3.1)^{b c A}$ \\
\hline Pflow-3s & $54.1(0.2)^{a b c A}$ & $53.5(1.2)^{a b c A}$ & $66.6(0.3)$ abcB & $66.0(1.6)^{a b c B}$ \\
\hline Pflow-5s & $55.4(0.9)^{\mathrm{aA}}$ & $55.6(1.8)^{\mathrm{adA}}$ & $66.4(0.4)$ abcB & $68.0(1.8)^{a b c B}$ \\
\hline ECeram & $53.6(1.7)^{a b c A}$ & $52.7(3.4)^{a b c A}$ & $62.2(1.1)_{\mathrm{CA}}$ & $63.3(2.4)^{a b c A}$ \\
\hline EFlow & $59.0(1.6)^{\mathrm{aA}}$ & $57.1(0.7)^{\mathrm{aA}}$ & $71.0(1.4)^{\mathrm{aB}}$ & $68.9(0.7)^{a b B}$ \\
\hline
\end{tabular}



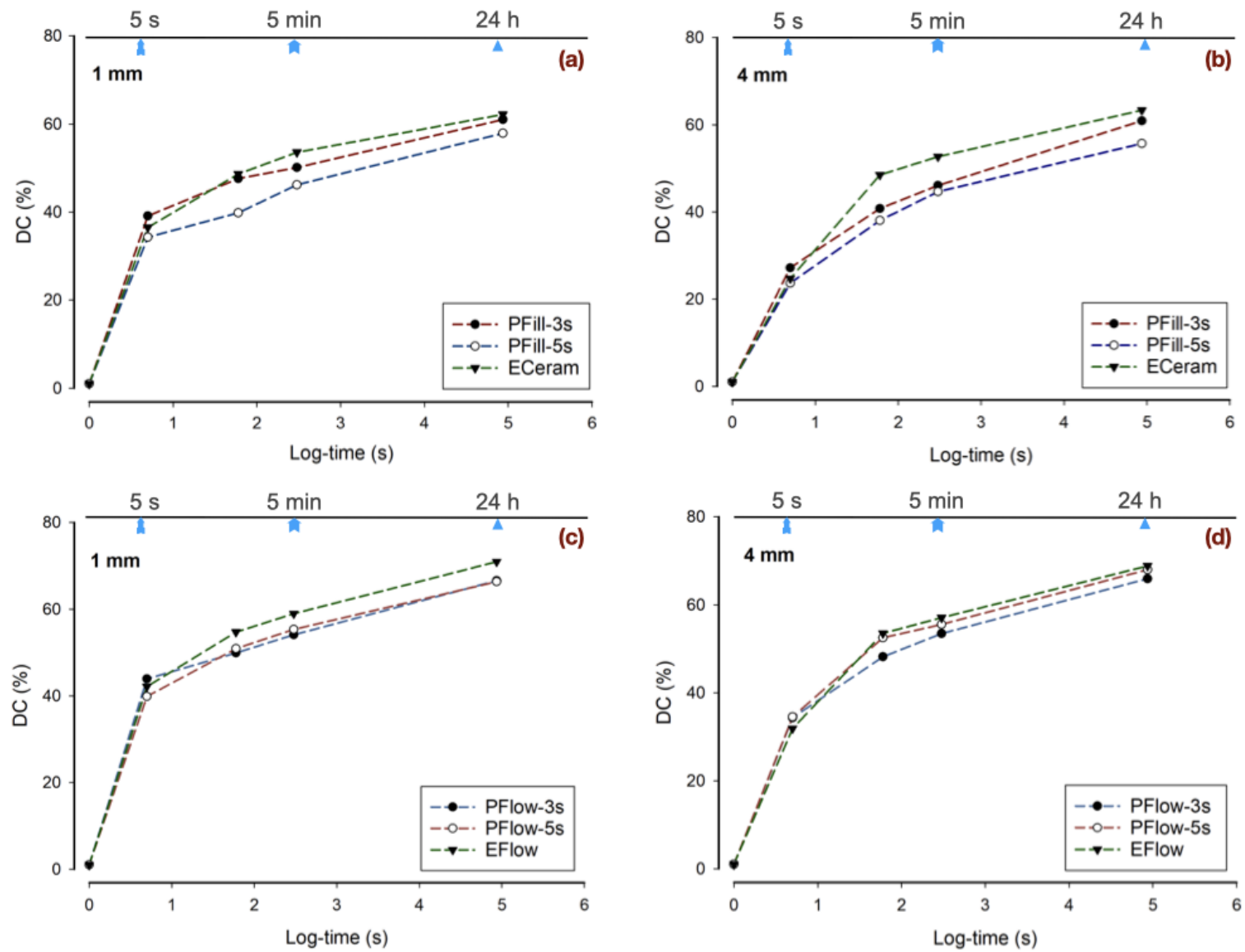

Figure 3: DC (\%) as a function of log-time up to $24 \mathrm{~h}$ for: PFill-3s, PFill-5s, and ECeram at (a) $1 \mathrm{~mm}$ and (b) $4 \mathrm{~mm}$ depths; PFlow-3s, PFlow-5s, and EFlow at (c) $1 \mathrm{~mm}$ and (d) $4 \mathrm{~mm}$ depths.

\section{Polymerization kinetics}

The change in DC in real time for the first $300 \mathrm{~s}$ were analysed and described by an exponential sum function, defined by the parameters $a, b, c$, and d (Equation 2; Figure 4; Table 4). 

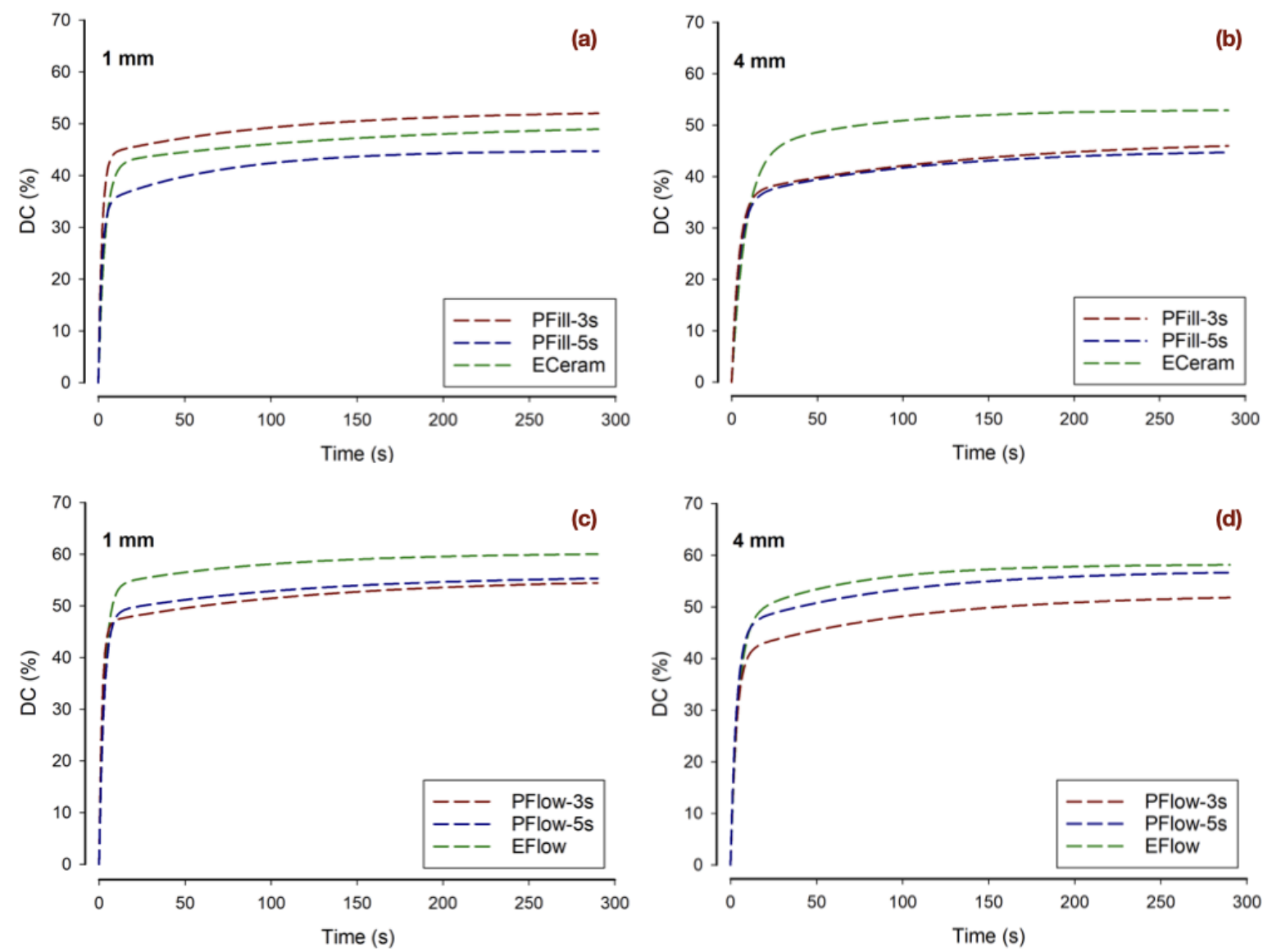

Figure 4: Real-time degree of conversion (DC \%) during the first 300 s postirradiation for: PFill-3s, PFill-5s, and ECeram at (a) $1 \mathrm{~mm}$ and (b) $4 \mathrm{~mm}$ depths; PFlow-3s, PFlow-5s and EFlow at (c) $1 \mathrm{~mm}$ and (d) $1 \mathrm{~mm}$ depths.

Table 4: Mean (SD) of conversion kinetic parameters for the dual-exponential function (equation 2 ) and the correlation factors $\left(R^{2}\right)$.

\begin{tabular}{|c|c|c|c|c|c|c|}
\hline \multirow{2}{*}{ Material } & \multirow[t]{2}{*}{ Thickness } & \multicolumn{4}{|c|}{ Parameters } & \multirow[t]{2}{*}{$\mathrm{R}^{2}$} \\
\hline & & a & $b$ & c & $d$ & \\
\hline \multirow[t]{2}{*}{ PFill-3s } & $1 \mathrm{~mm}$ & 43.9 (3.1) & $0.5(0.3)$ & $8.5(0.5)$ & $0.01(0.003)$ & 0.97 \\
\hline & $4 \mathrm{~mm}$ & $36.7(2.1)$ & $0.2(0.3)$ & $11.0(1.6)$ & $0.01(0.01)$ & 0.96 \\
\hline \multirow[t]{2}{*}{ PFill-5s } & $1 \mathrm{~mm}$ & $35.2(4.1)$ & $0.5(0.03)$ & 10.2 (1.9) & $0.01(0.01)$ & 0.97 \\
\hline & $4 \mathrm{~mm}$ & $36.0(0.7)$ & $0.2(0.02)$ & $9.7(2.6)$ & $0.01(0.003)$ & 0.97 \\
\hline \multirow[t]{2}{*}{ PFlow-3s } & $1 \mathrm{~mm}$ & 46.9 (1.5) & $0.6(0.1)$ & $8.7(0.4)$ & $0.01(0.002)$ & 0.99 \\
\hline & $4 \mathrm{~mm}$ & 41.2 (1.2) & $0.3(0.01)$ & $11.3(0.4)$ & $0.01(0.001)$ & 0.99 \\
\hline \multirow[t]{2}{*}{ PFlow-5s } & $1 \mathrm{~mm}$ & 48.7 (1.0) & $0.4(0.1)$ & $7.4(0.3)$ & $0.01(0.001)$ & 0.99 \\
\hline & $4 \mathrm{~mm}$ & $46.3(3.4)$ & $0.3(0.02)$ & $10.9(1.1)$ & $0.01(0.003)$ & 0.99 \\
\hline ECeram & $1 \mathrm{~mm}$ & $42.2(2.2)$ & $0.3(0.01)$ & $7.5(2.9)$ & $0.01(0.01)$ & 0.98 \\
\hline
\end{tabular}




\begin{tabular}{|l|l|l|l|l|l|l|}
\hline & $4 \mathrm{~mm}$ & $43.8(2.7)$ & $0.1(0.08)$ & $9.0(4.4)$ & $0.02(0.01)$ & 0.98 \\
\hline \multirow{2}{*}{ EFlow } & $1 \mathrm{~mm}$ & $54.0(0.8)$ & $0.3(0.01)$ & $6.6(0.6)$ & $0.01(0.003)$ & 0.99 \\
\cline { 2 - 7 } & $4 \mathrm{~mm}$ & $47.5(4.2)$ & $0.2(0.02)$ & $10.8(1.7)$ & $0.02(0.01)$ & 0.99 \\
\hline
\end{tabular}

The curve-fitted conversion parameters varied with the depth, materials evaluated and their viscosity. All materials, except PFill-5s and ECeram had higher " $a$ " and " $b$ " parameters, indicating faster conversion, at $1 \mathrm{~mm}$ - closer to the irradiated surface, compared to $4 \mathrm{~mm}$. By contrast, parameter " $\mathrm{c}$ " was lower at $1 \mathrm{~mm}$ depth compared to $4 \mathrm{~mm}$ (except for PFill5s). Parameter " $d$ " was invariant for all materials.

Considering the rate of polymerization (conversion; DC\%/s), the maximum rate, $\mathrm{RP}_{\max }$ occurred at about $5 \mathrm{~s}$, in all cases. It varied with material and specimen depth (Figure 5; Table 5), ranging across the specimen groups between $4.3-8.8 \% / s$ with correspondent DC RPmax ranging between 22.2-45.3\%. Material viscosity and specimen depth significantly influenced the $R P_{\max }(p<0.05)$. The highest $R P_{\max }$ was apparent for PFlow, irradiated for $3 \mathrm{~s}$ and ECeram showing the lowest $R P_{\max }$. $D C_{R P \max }$ was generally high for all materials, which strongly correlated with $\mathrm{RP}_{\max }(\mathrm{r}=0.96)$. That is, with higher rate of polymerization, high corresponding DC occurred.

As seen in Figure 5 (a), a further small peak in RP was apparent between 15-20 s for the PowerCure materials: PFill and PFlow at $1 \mathrm{~mm}$ depth; but much less apparent at $4 \mathrm{~mm}$. 

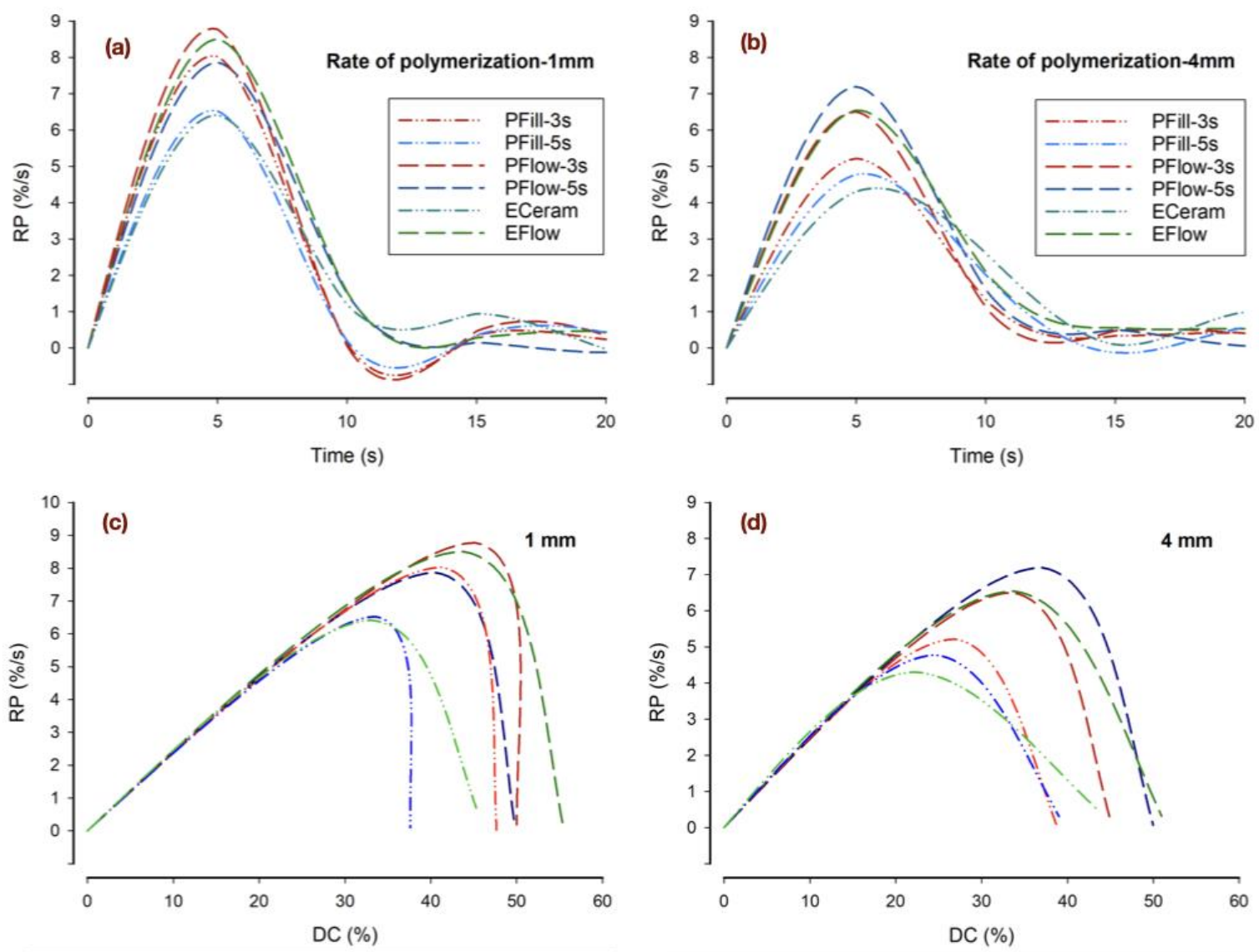

Figure 5: $(a, b)$ : Rate of polymerization RP (\%/s) versus time (s) for the first 20 $s$ of polymerization for: (a) $1 \mathrm{~mm}$ and (b) $4 \mathrm{~mm}$ depths as a function of material; $(c, d)$ : rate of polymerization versus degree of conversion (DC \%) for: (c) $1 \mathrm{~mm}$ and (d) $4 \mathrm{~mm}$ depth.

Table 5: Mean (SD) of maximum rate of polymerization $\mathrm{RP}_{\max }$ and the degree of conversion $D_{\text {RPmax }}$ at that time-point.

\begin{tabular}{|l|l|l|l|}
\hline Materials & thickness & $\mathbf{R P}_{(\text {max })}$ & $\begin{array}{l}\mathbf{D C}_{(\mathbf{R P m a x})} \\
\mathbf{( \% )}\end{array}$ \\
\hline PFill-3s & $1 \mathrm{~mm}$ & $8.0(0.5)_{\mathrm{ab}}$ & $41.3(2.8)$ \\
\hline & $4 \mathrm{~mm}$ & $5.2(1.2)_{\mathrm{cde}}$ & $26.8(5.9)$ \\
\hline PFill-5s & $1 \mathrm{~mm}$ & $6.7(1.1)_{\mathrm{abcd}}$ & $34.4(5.6)$ \\
\hline & $4 \mathrm{~mm}$ & $4.8(0.5)_{\mathrm{de}}$ & $24.6(2.6)$ \\
\hline PFlow-3s & $1 \mathrm{~mm}$ & $8.8(0.5)_{\mathrm{a}}$ & $45.3(2.7)$ \\
\hline & $4 \mathrm{~mm}$ & $6.5(0.2)_{\mathrm{bcde}}$ & $33.4(1.1)$ \\
\hline PFlow-5s & $1 \mathrm{~mm}$ & $7.8(1.0)_{\mathrm{a}}$ & $40.2(4.9)$ \\
\hline
\end{tabular}




\begin{tabular}{|l|l|l|l|}
\hline & $4 \mathrm{~mm}$ & $7.2(0.9) \mathrm{abc}$ & $36.9(4.5)$ \\
\hline ECeram & $1 \mathrm{~mm}$ & $6.4(0.4)_{\mathrm{bcde}}$ & $33.0(1.9)$ \\
\cline { 2 - 4 } & $4 \mathrm{~mm}$ & $4.3(1.6)_{\mathrm{e}}$ & $22.2(8.4)$ \\
\hline \multirow{2}{*}{ EFlow } & $1 \mathrm{~mm}$ & $8.5(0.2)_{\mathrm{ab}}$ & $43.8(1.0)$ \\
& $4 \mathrm{~mm}$ & $6.6(0.2)_{\mathrm{abcde}}$ & $33.7(0.8)$ \\
\hline
\end{tabular}




\section{Discussion}

This study was designed to evaluate the degree of conversion and polymerization kinetics of rapid-cure resin composites, as well as the effect of $24 \mathrm{~h}$ post-irradiation time and specimen thickness on their behavior. FTIR is widely accepted for measuring degree of conversion and polymerization kinetics [21, 24]. OPUS software (BRUKER OPTIK GmbH, Ettlingen, Germany) enabled integration and analysis of the FTIR spectral variations.

There are conflicting reports on the influence of delivering the same radiant exposure by different irradiance intensities on resin composite polymerization $[25,26]$. For PFill and PFlow materials cured in 3 and $5 \mathrm{~s}$, the polywave LCU was used to deliver 9 and $10 \mathrm{~J} / \mathrm{cm}^{2}$ radiant exposure respectively. That was less than half of the radiant exposure delivered to ECeram and EFlow control materials $\left(24 \mathrm{~J} / \mathrm{cm}^{2}\right)$. The high radiant exposure delivered to control groups were beyond the manufacturer recommended dose to ensure optimum polymerization and to compensate for the single (narrow) blue spectrum delivered by the LCU [5]. The high energy delivered in a short time via the wide-spectrum LCU was sufficient to produce an adequate $\mathrm{DC}$, due to the materials' ability to absorb energy from both types of wavelengths (violet and blue spectra) and its high reactivity to the lower wavelength [13, 27]. Having a type I photoinitiator in the evaluated materials, our findings were generally in line with the Bunsen-Roscoe exposure reciprocity law, which assume that the photoresponse depends on the radiant exposure rather than irradiance power and time [28-30]. Furthermore, the high irradiance used in PFill and PFlow produced sufficient DC after $24 \mathrm{~h}$ and mainly affected the polymerization kinetics, evidently seen at $1 \mathrm{~mm}$ depth.

DC measured at $4 \mathrm{~mm}$ thickness was at the clinically representative depth for bulk fill materials. $1 \mathrm{~mm}$ thick specimens were added to represent proximity to the surface layer. In our study, the thickness did not have a significant effect on the overall DC, which was reported previously $[19,31]$. Therefore, the first null hypothesis was retained. Moreover, the material viscosity did have a significant effect on conversion, with superior DC results and a significant increase for up to $24 \mathrm{~h}$ seen in flowable materials compared to nonflowable materials. At $5 \mathrm{~min}$, EFlow presented the highest conversion regardless of the thickness, with both PFlow-3s and PFlow-5s being comparable. However, ECeram was higher in its category (non-flowable) although PFill-3s and PFill-5s gave similar results. 
Monomer conversion continued significantly for over $24 \mathrm{~h}$, for most materials, with a minimum of $16.8 \%$ increase from $5 \mathrm{~min}$, thus the second null hypothesis was rejected.

After $24 \mathrm{~h}$ post-irradiation, all materials were generally comparable, reaching a clinically acceptable conversion degree for bulkfill resin composites (50-79\%), which also has been shown to continue for over 7 days post-irradiation [20, 23, 32-34]. The real time DC \% evaluation for $24 \mathrm{~h}$ in this study was at $23 \pm 1^{\circ} \mathrm{C}$ tempereture, which might be considered a limitation. The ambient intra oral temperature might have promoted higher DC [35].

The termination phase of polymerization mostly occurs as a result of rapid increase in internal molecular stiffness, restricting molecular movement and diffusion, rather than termination by total conversion (or coupling or disproportionation). This explains the prolonged conversion over time [36].

The polymerization kinetics in our study were investigated by the use of an exponential sum function, based on superposition of two exponential functions representing the gel (parameters $a$ and b) and glassy vitrification (parameters $c, d$ ) phases [24]. All materials, except PFill-5s and ECeram had higher " $a$ " and " $b$ " parameters, indicating faster conversion, at $1 \mathrm{~mm}$ compared to $4 \mathrm{~mm}$. More specifically, parameter "a" was apparently materialdependent as ECeram and EFlow were slightly higher than PFill and PFlow materials for both thickness (except ECeram, $1 \mathrm{~mm}$ ), this could also can be related to the higher radiant exposure (over longer time) delivered to these materials. Parameter " $b$ " reflects the gel phase in relation to gradient steepness. A $1 \mathrm{~mm}$ depth exhibited a higher " $b$ " parameter indicating higher $\mathrm{C}=\mathrm{C}$ double bond conversion compared to $4 \mathrm{~mm}$ thick specimens. That is, a lower parameter $b$ indicated a somewhat delayed gel-point in deeper zones, suggesting possibly fewer network crosslinks $[19,24]$. Moreover, the higher " $b$ " parameter seen in PFill and PFlow compared to ECeram and EFlow indicating faster gelation of these highly irradiated composites, which could be further investigated [18].

The main structural monomer composition of the evaluated materials was mostly similar, with only a few important modifications to PFill and PFlow. These were: (1) the elimination of Lucerin TPO, (2) addition-fragmentation chain transfer (AFCT) reagent, (3) addition of tricyclodocane dimethanol dimethacrylate (DCP) monomer and (4) addition of propoxylated Bisphenol A dimethacrylate monomer. AFCT reagent ( $\beta$-allyl sulfone) is the main 
modification, present to modify the polymerization mechanism by controlling the polymer architecture and end group functionality. This methacrylate reagent has shown to enhance the overall properties of the polymer by improving the homogeneity, glass transition temperature and mechanical properties, thus possibly to overcome the polymerization shrinkage and shrinkage stress associated with higher irradiance [17].

The $\mathrm{RP}_{\max }$ occurred at $5 \mathrm{~s}$, mainly affected by specimen thickness and material viscosity. PFlow and PFill materials cured for $3 \mathrm{~s}$ had the highest $\mathrm{RP}_{\max }$ in $1 \mathrm{~mm}$ thickness, explained by high irradiance received in low depth. As light transmission reduced in deeper layers, following the Beer-Lambert law, $\mathrm{RP}_{\max }$ reduced [19]. Following the main propagation phase of polymerization in AFCT-methacrylate-containing materials, a second, minor peak was apparent after $15 \mathrm{~s}$ in the $\mathrm{R}_{\mathrm{p}}$ plot measured at $1 \mathrm{~mm}$ depth (Figure $5 \mathrm{a}$ ). This suggests further network conversion and may be due to rapid thermal diffusion from 0 to $1 \mathrm{~mm}$, under semiadiabatic conditions, through the heating effect of the PowerCure LCU $[18,36]$. Furthermore, high irradiance received by the resin composite materials can cause a slight delay in auto-acceleration to occur at higher $\mathrm{DC}$ leading to generally higher $\mathrm{DC} \mathrm{RPmax}_{\mathrm{x}}$, as seen in our study [30,37]. Furthermore, a strong positive correlation $(r=0.96)$ seen between higher $\mathrm{RP}_{\max }$ and $\mathrm{DC} \mathrm{RPmax}_{\mathrm{m}}$ indicating sufficient conversion even with high conversion rate.

PFlow and EFlow generally outperformed the non-flowable materials PFill and ECeram in their overall DC and kinetics. High concentration of highly-viscous monomers with high molecular weight, such as Bis-GMA and UDMA, can hinder the radicals and monomer movements significantly, which affects their reactivity compared to materials with lower viscosity $[19,38,39]$. High filler content, independent of the filler type, was also associated with limiting conversion, seen in highly-filled materials, causing molecular mobility restriction $[40,41]$.

The AFCT reagent added to methacrylate-based resin composites produced an equivalent overall conversion to their comparators in our study as well as others [18]. While polymerization related properties can be evaluated during polymerization via DC, further investigation is needed to explore the effect of AFCT reagent on polymerization shrinkage as well as early viscoelastic properties, specifically in the early glass stage. The crosslink density 
and the long-term stability against chemical degradation of the matrix network should also be investigated.

\section{Conclusion}

PFill and PFlow materials produced an overall comparable conversion at clinically relevant times, $5 \mathrm{~min}$ and $24 \mathrm{~h}$ post-irradiation, despite the ultra-short irradiation times, regardless of the specimen depth. Polymerization kinetics and the rate of polymerization were significantly influenced by specimen thickness and material viscosity.

\section{Acknowledgements}

The authors thank Ivoclar-Vivadent AG for provision of composite materials.

The authors declare no conflict of interest. 


\section{REFERENCES}

1. Kopperud S, Rukke H, Kopperud H, Bruzell E. Light Curing Procedures-Performance, Knowledge Level and Safety Awareness among Dentists. J Dent, 2017; 58: 67-73.

2. Demarco F, Corrêa M, Cenci M, Moraes R, Opdam NJ. Longevity of Posterior Composite Restorations: Not Only a Matter of Materials. Dent Mater, 2012; 28: 87-101.

3. Watts DC. Let There Be More Light! Dentl Mater, 2015; 31: 2.

4. Silikas N, Eliades G, Watts DC. Light Intensity Effects on Resin-Composite Degree of Conversion and Shrinkage Strain. Dent Mater, 2000; 16: 292-296.

5. Al-Ahdal K, Ilie N, Silikas N, Watts DC. Polymerization Kinetics and Impact of Post Polymerization on the Degree of Conversion of Bulk-Fill Resin-Composite at Clinically Relevant Depth. Dent Mater, 2015; 31: 1207-1213.

6. Santini A, Gallegos IT, Felix CM. Photoinitiators in Dentistry: A Review. Prim Dent J, 2013; 2: 30-33.

7. Price RB, Ferracane JL, Shortall AC. Light-Curing Units: A Review of What We Need to Know. J Dent Res, 2015; 94: 1179-1186.

8. Aguiar FH, Lazzari CR, Lima DA, Ambrosano GM, Lovadino JR. Effect of Light Curing Tip Distance and Resin Shade on Microhardness of a Hybrid Resin Composite. Braz Oral Res, 2005; 19: 302-306.

9. Ferracane JL, Condon JR. Rate of Elution of Leachable Components from Composite. Dent Mater, 1990; 6: 282-287.

10. Bernardo M, Luis H, Martin MD, Leroux BG, Rue T, Leitao J, DeRouen TA. Survival and Reasons for Failure of Amalgam Versus Composite Posterior Restorations Placed in a Randomized Clinical Trial. J Am Dent Assoc, 2007; 138: 775-783.

11. Collins CJ, Bryant RW, Hodge KL. A Clinical Evaluation of Posterior Composite Resin Restorations: 8-Year Findings. J Dent, 1998; 26: 311-317.

12. Heintze SD, Rousson V. Clinical Effectiveness of Direct Class li Restorations - a Meta-Analysis. J Adhes Dent, 2012; 14: 407-431.

13. Daugherty MM, Lien W, Mansell MR, Risk DL, Savett DA, Vandewalle KS. Effect of HighIntensity Curing Lights on the Polymerization of Bulk-Fill Composites. Dent Mater, 2018; 34: 1531-1541.

14. Besegato JF, Jussiani El, Andrello AC, Fernandes RV, Salomao FM, Vicentin BLS, DezanGarbelini CC, Hoeppner MG. Effect of Light-Curing Protocols on the Mechanical Behavior of Bulk-Fill Resin Composites. J Mech Behav Biomed Mater, 2019; 90: 381-387.

15. Rueggeberg FA, Giannini M, Arrais CAG, Price RBT. Light Curing in Dentistry and Clinical Implications: A Literature Review. Braz Oral Res, 2017; 31: e61.

16. Ferracane JL. Hygroscopic and Hydrolytic Effects in Dental Polymer Networks. Dent Mater, 2006; 22: 211-222.

17. Gorsche C, Griesser M, Gescheidt G, Moszner N, Liska R. B-Allyl Sulfones as AdditionFragmentation Chain Transfer Reagents: A Tool for Adjusting Thermal and Mechanical Properties of Dimethacrylate Networks. Macromolecules, 2014; 47: 7327-7336.

18. Ilie N, Watts DC. Outcomes of Ultra-Fast (3 S) Photo-Cure in a Raft-Modified ResinComposite. Dent Mater, 2020; 36: 570-579.

19. Ilie N. Impact of Light Transmittance Mode on Polymerisation Kinetics in Bulk-Fill ResinBased Composites. J Dent, 2017; 63: 51-59.

20. Par M, Gamulin O, Marovic D, Klaric E, Tarle Z. Raman Spectroscopic Assessment of Degree of Conversion of Bulk-Fill Resin Composites-Changes at 24 Hours Post Cure. Operative dentistry, 2015; 40: E92-E101. 
21. Ferracane J, Hilton T, Stansbury J, Watts D, Silikas N, Ilie N, Heintze S, Cadenaro M, Hickel R. Academy of Dental Materials Guidance-Resin Composites: Part li-Technique Sensitivity (Handling, Polymerization, Dimensional Changes). Dent Mater, 2017; 33: 1171-1191.

22. Moraes LG, Rocha RS, Menegazzo LM, de Araujo EB, Yukimito K, Moraes JC. Infrared Spectroscopy: A Tool for Determination of the Degree of Conversion in Dental Composites. J Appl Oral Sci, 2008; 16: 145-149.

23. Par M, Lapas-Barisic M, Gamulin O, Panduric V, Spanovic N, Tarle Z. Long Term Degree of Conversion of Two Bulk-Fill Composites. Acta Stomatol Croat, 2016; 50: 292-300.

24. Ilie N, Durner J. Polymerization Kinetic Calculations in Dental Composites: A Method Comparison Analysis. Clin Oral Investig, 2014; 18: 1587-1596.

25. Hadis M, Leprince JG, Shortall AC, Devaux J, Leloup G, Palin WM. High Irradiance Curing and Anomalies of Exposure Reciprocity Law in Resin-Based Materials. J Dent, 2011; 39: 549-557.

26. AlShaafi MM. Effects of Delivering the Same Radiant Exposures at 730, 1450, and 2920 $\mathrm{Mw} / \mathrm{Cm} 2$ to Two Resin-Based Composites. Eur J Dent, 2017; 11: 22.

27. Leprince J, Hadis M, Shortall A, Ferracane J, Devaux J, Leloup G, Palin W. Photoinitiator Type and Applicability of Exposure Reciprocity Law in Filled and Unfilled Photoactive Resins. Dent Mater, 2011; 27: 157-164.

28. Bunsen RW, Roscoe HE. Photochemische Untersuchungen: Engelmann; 1892.

29. Randolph LD, Palin WM, Watts DC, Genet M, Devaux J, Leloup G, Leprince JG. The Effect of Ultra-Fast Photopolymerisation of Experimental Composites on Shrinkage Stress, Network Formation and Pulpal Temperature Rise. Dent Mater, 2014; 30: 1280-1289.

30. Palagummi SV, Hong T, Wang Z, Moon CK, Chiang MYM. Resin Viscosity Determines the Condition for a Valid Exposure Reciprocity Law in Dental Composites. Dent Mater, 2020; 36: 310-319.

31. Wang R, Liu H, Wang Y. Different Depth-Related Polymerization Kinetics of Dual-Cure, BulkFill Composites. Dent Mater, 2019; 35: 1095-1103.

32. Watts DC, Amer OM, Combe EC. Surface Hardness Development in Light-Cured Composites. Dent Mater, 1987; 3: 265-269.

33. Alshali RZ, Silikas N, Satterthwaite JD. Degree of Conversion of Bulk-Fill Compared to Conventional Resin-Composites at Two Time Intervals. Dent Mater, 2013; 29: e213-217.

34. Czasch P, Ilie N. In Vitro Comparison of Mechanical Properties and Degree of Cure of Bulk Fill Composites. Clinical oral investigations, 2013; 17: 227-235.

35. Calheiros C, Daronch M, Rueggeberg F, Braga R. Effect of Temperature on Composite Polymerization Stress and Degree of Conversion. Dent Mater, 2014; 30: 613-618.

36. Burtscher P. Stability of Radicals in Cured Composite Materials. Dent Mater, 1993; 9: 218221.

37. Lovelh L, Newman S, Bowman C. The Effects of Light Intensity, Temperature, and Comonomer Composition on the Polymerization Behavior of Dimethacrylate Dental Resins. J Dent Res, 1999; 78: 1469-1476.

38. Abu-elenain DA, Lewis SH, Stansbury JW. Property Evolution During Vitrification of Dimethacrylate Photopolymer Networks. Dent Mater, 2013; 29: 1173-1181.

39. Miletic V, Pongprueksa P, De Munck J, Brooks NR, Van Meerbeek B. Curing Characteristics of Flowable and Sculptable Bulk-Fill Composites. Clin oral investig, 2017; 21: 1201-1212.

40. Shah PK, Stansbury JW. Role of Filler and Functional Group Conversion in the Evolution of Properties in Polymeric Dental Restoratives. Dent Mater, 2014; 30: 586-593.

41. Halvorson RH, Erickson RL, Davidson CL. The Effect of Filler and Silane Content on Conversion of Resin-Based Composite. Dent Mater, 2003; 19: 327-333. 